\section{THE MORON AND THE STUDY OF ALIEN} DEFECTIVES

\author{
HOWARD A. KNOX, M.D. \\ Assistant Surgeon, U. S. Public Health. Service \\ ELIIS IStAND, N. Y.
}

In no branch of the science of medicine does a lay diagnosis have weight in a court of law as it does in mental aberration. In most types of active insanity - there are manifest and obvious symptoms which brand the possessor as "crazy" in the eyes of the laity. For instance, the testimony of a lay person has been admitted to substantiate the sanity of a person making a will on his death-bed. In many cases of the systematized delusions (paranoia) without deterioration, the interval manic-depressive and certain alcoholic hallucinosis cases of a mild type there may be external evidence of insanity to the layman, but in some cases this is lacking. There is one great class of defectives of tremendous importance from a eugenic, social and economic point of view that is not ordinarily recounized by laymen as defectives. This class comprises the morons and constitutional inferior types. These terms are not at all synonymous but stand for classes which partake of some of the characteristics of each other. The two have in common latent or undeveloped moral tone, limited ability for coordinated and consecutive mental effort, erratic judgment and inability to compete unaided in struggle for existence.

The differentiation is best made by the system devised tion the French psychologist, Dr. Binet, or by a modification to suit the class of cases in question. It would be manifestly absurd to use educational tests in the case of be fueated persons. The moron adult at puberty will be found to be several years younger mentally than he is physically; his brain will organize at this point, and he old can become any older mentally. " $\mathrm{A}$ man is as old as his arteries" and as young as his brain. 'The constitutional inferior, however, may respond to the The mests for normal persons of his physical years. leeds moron can contribute nothing to society, but he leeds protection for himself and niost of his offepring. wing to his inability to get on in the world.

While an officer in the medical corps of the Army, I observed and exmmined men who were perfect specimens physically but who mentally were but children, glad of the protection offered by the well-ordered life and excellent care of the Service. They had tried various work in civil life but could not succeed and were referred to by their co-workers and employers as "dumb," "wooden" or "thick." These men of course are not wanted by the Army or any other organization in which men are sometimes called on to think for themselves o1' moron on their own initiative. Such men belong in the groups.

In certain rural communities several miles from a railway a majority of the inhabitants are mentally deficient and one or two perhaps are in the "town fool" class. This is usually due to near or remote consanguinity. The people in these communities probably tious heard of Mendel or his theory, but the conscigntrous doctor and minister in such places should know with profit by it; they should know that normal parents child normal ancestry can bring forth only normal children who are incapable of transmitting a neuropathic constitution to their offspring. They should also all wh realize that if both parents are neuropathic all their children will be netropathic also.
$A^{*}$ drop of ink in a barrel of water does not make ink, but the greater the number of ilrops of ink in that barrel of water the more inky it becomes. Likewise eviry defective, both mental and physical, that enters this country or is born in it is anotlier drop of ink and may become a parent who will fulfill one of the many theoretical expectations of Méndel and will surely produce defective progeny.

This progeny, if not actually insane, has a constitutional psychopathic predisposition - in other words, potential insanity - and is waiting only for adversity, change of enviromment, alcohol, syphilis or some other contributing cause to become actually insane and a public charge.

The detection of higher defectives is a science that could well demand the attention of teachers and jurors. for it is in the school-house and the court-house that most young lives are saved or lost. There are hundreds of minor's in reformatories that slould be in trainingschools for the feeble-minded, and if delinquents and prostitutes were regarded as mental defectives in the eyes of the law and appropriate means taken to inhibit jrocreation, the social problem would be practically settled, at least for our great-grandehildren.

There are perhaps more unclassified entities in psychiatry than in any other branch of medicine. It is easiest to detect insanity in the type of people with whom one has most often been associated; but when one reaches out to examine a subject with whom one has not a thing in common it is a different proposition that can be met only by studying many normal subjects of the same kind and by being possessed of a keen natural ability for psycho-analysis apart from the acquired ability to detect mental disease.

I refer especially to the alien insane as observed in lospitals in this country. Experience with the various races convinces an observer that each alien has a more or less distinct set of psychosic attributes due to his environnent, natural attributes and degree of inherent intelligence. In working with these cases one must never lose sight of the fact that each expression of thought that comes out of the mind must at some previous time have gone into it, and for this reason it is foolish and useless is ask a man to tell time who has never seen or heard of a time-piece.

At this point, however, the normal person, no matter how ignorant he may be or to what race he may belong, can be separated from the noron or higher defective in that the normal person has a practically unlimited capacity for absorbing knowledge properly prepared for him, while the moron can learn only to a certain limited point which must suffice.

As a student must be thoroughly acquainted with normal histology before he can take up the study of pathology, so must he know thoroughly a normal Italian, Greek or Pole before he can study or hope to recognize a mentally defective one. This is especially true in regard to psychoses in their incipiency and to conditions of feeble-mindedness.

Paresis in an educuted American business man is hardly the same, in the early stages at least, as the same disease in an alien from Southern Europe.

'To the uninitiated using routine tests for defectives nearly all the peasants from certain Huropean countries appear to be of the moron type; but of course this is a fallacy. If these peasants are questioned about con ditions existing in the land from which they come most cf them will show average intelligence. 
In making tests on these people the following conditions should be fulfilled:

1. T'ise interpreter should have a pleasant and kindly manner; lie must be accurate in his statements and convey the exact thought and intent of the alien and he must be unbiased, impartial and above all else intelligent. The interpreter, like the "examiner, should have special training.

2. A quiet, well-ventilated room should be used for the examination.

3. The condition of the alien should be taken into consideration; for instance, after ten days of sea-sickness, fatigue and excitement he could not be expected to do himself justice. Rest, food and reassurance are to be prescribed here in generous quantities.

'The alien in most cases should be given the benefit of the doubt if there is any, but it must be remembered that the alien will usually deny hereditary taint and in every way minimize his symptoms to suit his purpose, just as some soldiers will magnify theirs on a hot day with a long march in prospect.

With special reference to the examination of immigrants it may be said that the detection of morons or ligher defectives is of vastly more importance than the detection of the insane, for the reason that the insune or potentially insane will soon be recognized after landing and placed in an asylum or deported so that in either event they cannot propagate and affect the race adversely. On the other hand, the moron will not be recognized and will immediately start a line of defectives whose progeny, like the brook, will go on forever, branching off here in an imbecile and there in an epileptic, costing the country millions of dollars in court fees and incarceration expenses.

\section{THE DETECTION OF THE MENTALLY DEFECTIVE AMONG IMMIGRAN'IS}

\author{
C. P. KNIGIT, M.D.
}

Assistant Surgeon, U. S. Publle Health Service ELIIS ISLAND, N. Y.

It will be the purpose of this paper to discuss, not the detection of the insane, but the detection of the idiot, the imbecile and the feeble-minded seeking admission to this country.

In this day of large immigration there is scarcely a ship coming into the port of New York which does not carry among its passengers a mental defective of some degree. One of the duties of the medical officer detailed for line inspection in immigration work is to detect such cases and detain them for further mental diagnosis. One can readily see the difficulties presented by the admixture of races coming on each ship and the want of time for conducting such examinations. Aliens of the cabin class are examined on shipboard on the way from quarantine to the docks. The examination is especially difficult, owing to the lack of accommodations, of light, of space, to the excessive noise from the machinery and to the general confusion at the docks, all of which detract from the efficiency of the examination.

The present-day immigration gravely concerns the nation as a whole, and the importance of the detection of the mentally defective is apparent when we stop to reflect on the following data. Figures presented by Dr. T. W. Salmon, ${ }^{1}$ of the New York State Board of Alienists, show that the State of New York receives 26 per

1. Sulmon, T. W.: Insanity nnd the lmmigrutlon Lalv, New York state Hosp. Buil., Noverober, 1011. cent. of all immigrants coming into the United States and is the destination of more than 80 per cent. of the immigrants found on arrival to be insune or mentally defective. Under the headings of idiots, imbeciles and feeble-minded, the New York Socjety for the Prevention of Cruelty to Children has investigated these conditions among children of the sthool age and reports ${ }^{2}$ that there are 7,000 distinctly feeble-minded children in New York or 1 per cent. of the school population. This is in addition to the idiots and imbeciles and does not include the morally defective or the border-line cases. Census statistics show that 30 per cent. of the feeblemincled children in the general population of the United States are the progeny of aliens or naturalized citizens. The financial outlay for caring for this class of pcople is enormous. Dr. Anna Moore ${ }^{3}$ states that to support a feeble-minded person in one of the state institutions costs the state, on the average, $\$ 161.20$ a year. The financial side of the question is interesting, but more important is the influence of mental defectiveness on the future race of the country. It is an undisputed fact that the feeble-minded are as a class highly prolific. The report of the British Royal Commission for 1908 on the care and control of the feeblc-minded showed the birth-rate and the death-rate to be abnormally high; these defectives tend to have many children of whom a great many survive in spite of the high death-rate. The suggestions of Dr. Moore on the control of procreation among the feeble-minded, such as a proper segregation law and an efficient marriage law, to reduce the percentage of the mentally defective, are ideal for the present existing conditions, but more effective will be the removal of one of the principal causes, by reducing to a minimum the entrance into this country of the mentally and morally low type of alien. Immigration largely contributes to the high percentage of this class in the United States.

"Under the name phrenasthenia are comprised all forms of defective evolution of the mind. They constitute a very numerous family which differ widely from one another, from the state of almost absolute amentia to the numerous and multiple interlockings of weaklings who live mingled with the weaker normal individuals, but in all cases differ from those who in each country give the mean standard of mentality of the race concerned." 4 On primary inspection we do not concern our'selves with the degree of defectiveness mentally but endeavor to determine the certainty of a defect, still we cannot free ourselves from the traditional nomenclature of idiots, imbeciles and feeble-minded, althougls it is not best to regard these as designating well-distinguished groups, as they arc all simply degrees of defective mental evolution.

The idiot is a type which is usually easily recognized. The physician with the ordinary medical training or the layman will detect one when seen. Perhaps this state may not be recognized quickly in the very young but on close inspection the usual stigmata of degeneration present themselves, the most important of which are such anomalies as the low receding forehead and flat occiput with marked asymmetry. The size of the face is disproportionate to that of the cranium, either too large or too small, with deviated or flat nose and excessively deep orbits, the latter due to the protrusion of the superciliary ridges. The ears are deformed, enlarged,

2. Specinl Report to the Board of Directors, New Yol'k Soclety for Prevent. of Cruelty to Chlldren, Feb, 13, 1912.

3. Moore, Anna: Report I'repared for the l'ublic Education Assn. of New York, Juue, 1911.

4. Binuchl : 'lext-Book on Psychlatry, page 429, edit. 1906. 